\title{
INTELLIGENT ROBOTRONICS - METHODOLOGY FOR SOLVING Logical Problems of Service Robots
}

\author{
V.E., Pryanichnikov, V.V. Chernyshev, O.I. Davydov, B.Katalinic, R.V. \\ Khelemendik, K.V. Kharin, S.V. Kuvshinov, A.A. Roganov \& A.S.Travushkin
}
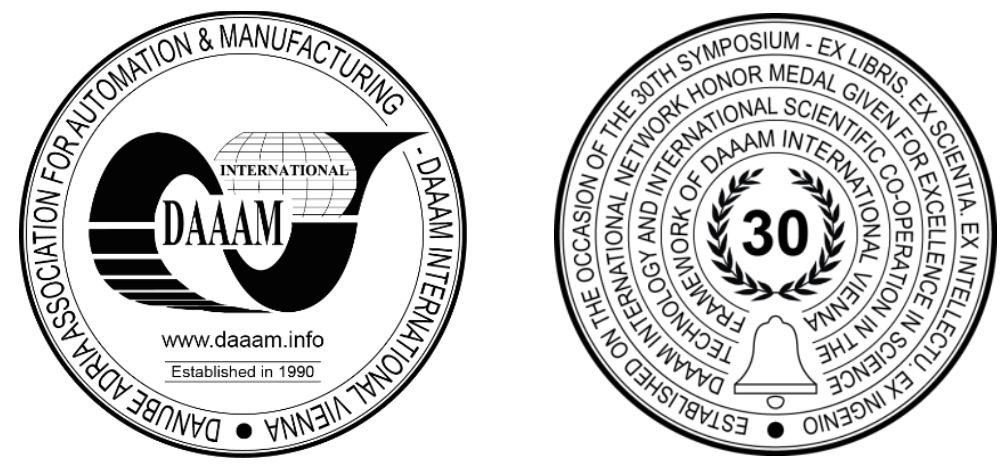

This Publication has to be referred as: Pryanichnikov, V[alentin]; Chernyshev, V[adim]; Davydov, O[leg]; Katalinic, $\mathrm{B}$ [ranko]; Khelemendik, R[oman]; Kharin, K[onstantin]; Kuvshinov, S[ergey]; Roganov, A[ndrey] \& Travushkin, A[lexandr] (2019). Intelligent Robotronics - Methodology for Solving Logical Problems of Service Robots, Proceedings of the 30th DAAAM International Symposium, pp.1131-1135, B. Katalinic (Ed.), Published by DAAAM International, ISBN 978-3-902734-22-8, ISSN 1726-9679, Vienna, Austria

DOI: $10.2507 / 30$ th.daaam.proceedings. 158

\begin{abstract}
The aim of the research was to find ways and means of unification of the hardware level of robotic and industrial systems, underwater robots, as well as combining these approaches with the developed technologies of intellectualization of sensor-control systems. The base of these works was the development of the integration, distributed software for a group development and control robotarium, including 3D-simulation, running in real time. Currently, 14 robots and manipulators, 4 industrial stands, 3 cameras with 3-coordinate control are involved into the joint research, and a system of tunable remote control of the realized workshop is created. A mechatronic complex was created - a joint distributed scientific and experimental laboratory-robotariums, which are actively used for scientific and educational purposes in the joint research on the agreement (05.03.2016) between KIAM Russian Academy of Sciences, IINET RSUH, MSTU "Stankin", TU Vienna, St.-Petersburg State Technical University and other organizations on the project "Intelligent robotronics".
\end{abstract}

Keywords: mobile service robots; underwater walking robots with supervisory control; intelligent robotics; sensorics.

\section{Introduction}

Thanks to the unification of the process of integration of different types of mechatronic devices and the construction of appropriate software, it was possible to repeatedly reduce the path from the construction of low-level sensor control systems to intelligent algorithms, that implement deductive mechanisms. Models of the robot environment have been created, which allow to automatically generate control plans, based on data from ultrasonic, television and laser sensors, including using parallel calculations. Obtained as a result of the research, new programming technologies can significantly (up to 10 times) accelerate the process of development of new technology through distributed access and special organization of interaction of software components. The use of logic and the creation of IGEC-technology allows intellectualize the work of distributed groups of robots in extreme conditions, thereby removing the load from the operator and ensuring the improvement of quality indicators (accuracy, speed). The developed principles of control of mechatronic 
devices complexes have found application in the creation of remote control of complex tunable production by the type of Industry 4.0. We will list in more detail the most significant results obtained in the course of work.

Developed software and information platform combine the work of a large number of mechatronic devices (through various data channels) and provide the ability to program and reprogram robots and devices without stopping their operation for reboot, recompilation. Load testing had shown the possibility of simultaneous operation of hundreds and thousands of such devices in real time, while well-known software packages in these conditions work slower. Testing was conducted on robots Amurs (our development), Robotino and others, are housed in several laboratories robotarium, as well as the simultaneous launch of 800 and 4000 virtual simulators, operating in real-time. The experiments confirmed all the advantages of the proposed approach, including the implementation of unified access to robotic complexes. It was also possible to radically reduce the unreasonably high costs associated with the installation, upgrade and maintenance of the equipment and the software environment running on it.

Application of the developed simulators are based on the actor model and other solutions for distributed control allowed for the first time within a single software platform to combine programming and control of parallel virtual models of mobile robots and their prototypes. At the same time, a unified simultaneous access of large groups of developers to the network of robotariums and to simultaneously launched multi-agent simulators with detailed 3D models. The technology of programming of movements of mobile service robots with the help of the developed designer of synergies is created.

To assess the possibilities of realization of communicative functions in the group of mobile robots carried out the prototyping of laser communication between robots via device targeting and capturing a light beam with the use of FPGAs in the system of technical vision.

To solve the problems of contactless power transmission and large information flows, an communication wave device was developed, especially relevant for underwater robots and for operation in other extreme environments. The advantage of the development is to eliminate the need for direct contact of the mobile underwater robot with a stationary charging service station - underwater walking vehicle, which allowed to work without surfacing, to accelerate the recovery of performance and reset the accumulated information, to achieve a high efficiency of antennas in salt water.

When building a supervisory control of robots, even in extreme conditions, it is permissible to use Wi-Fi wireless communication (for example, we had implemented the transmission of multi-stream video for emergency robots of the Brock-110/330 series). However, in this case, there are two problems - it is necessary to predict the signal attenuation at the exit from the zone of stable reception and to switch control to the automatic return algorithm. Previously, we have tested a number of ways to assess the quality of communication. This paper proposes a computational approach for the preliminary assessment and visualization of the Wi-Fi coverage of the working area of the service robot. An experimental study of this method was carried out in the robotarium (International Institute of new education technologies RSUH Keldysh institute of applied mathematics Russian Academy of sciences), consisting of a big set of rooms in which the service robots Amur-307, Amur-105, Robotino are controlled.

To control the service robot, the technology of seamless roaming (handover) was implemented - providing Wi-Fi coverage, in which, in the presence of several access points, stations (clients), moving between coverage areas, can switch from one point to another without loss of signal.

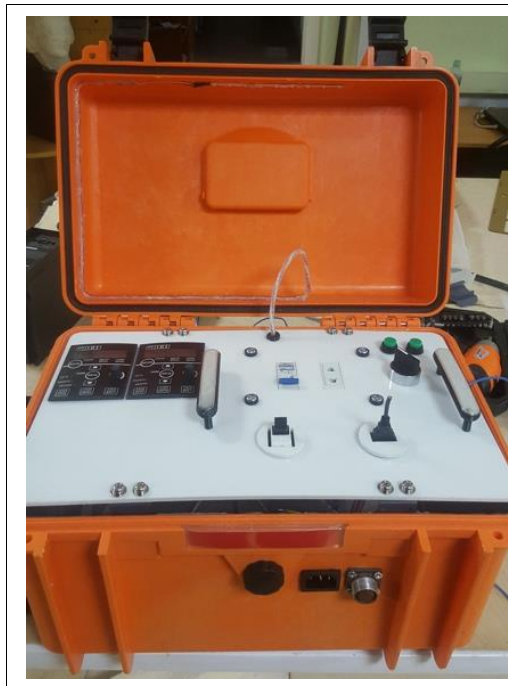

(a)

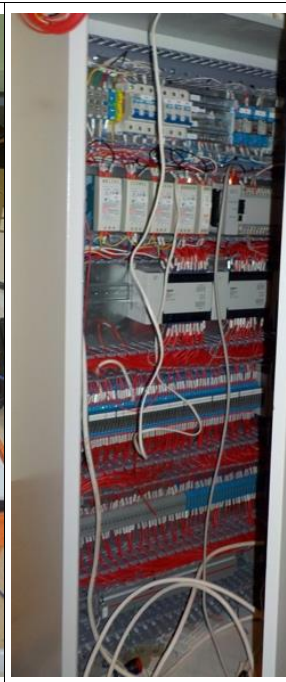

(в)

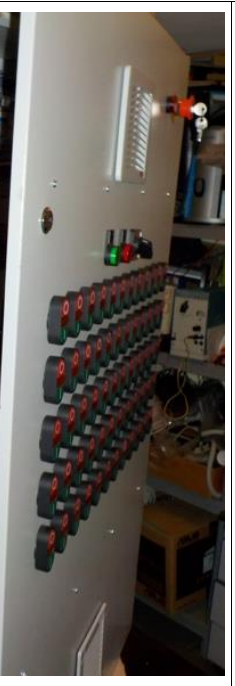

(c)

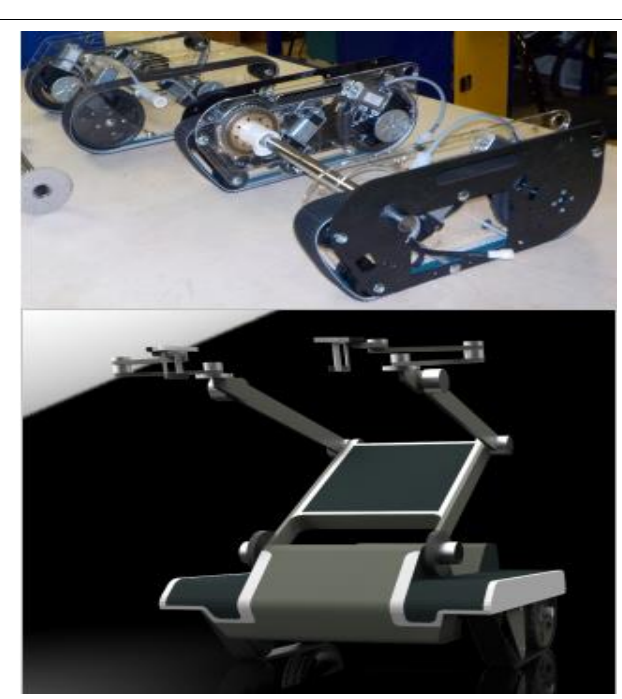

Figure 1. Examples of applications of the developed software and hardware - underwater robot control, shows the supervisory control panel (a), shop control system, one of the dozens of implemented software control racks with builtin logical analysis of failures and switching formulations (b), modeling and simulation of service mobile robot Amur307 , the creation of control algorithms for use in the developed service transport system for telemedicine (c). 


\section{The direction of intellectualization of the robotic systems}

One of the key problems in robotic research is the construction of new mechanisms of heuristic deduction, ensuring the minimization of iterative procedures, increasing the flexibility of interfaces between operators and robots, effective analysis of conflicting data from various sources. Let us explain the need to develop a new approach on the example of figure 2. The service robot has a voice interface with a limited set of commands (about 100 keywords). The robot must be able to independently perform transport and search actions. For example, the operator says the task: "take the screwdriver N1", "in room N2", "go", "in room N3", "put on the table N4", "go", "in room N5". Next, the robot recognises the sequence of operations and performs mission planning.

The task for the scheduler is sorted into separate sub-tasks, the correctness of the domain description is checked, the task is translated into a special language, into compact internal representations [5]. The initial data for the task execution have different levels of availability (Figure 2) for robot decision making: 1. A complete plan of the BTI, and even more so with the calculation of the availability zones of communication with the operator, for a mobile robot, as a rule, is not available, and trips to the appropriate areas of loss of communication must be programmed with the appropriate return algorithms (several independent principles of data transmission are used); 2.

The plan of available passages, which must be set to the robot with room numbers (connectivity graph), may also contain inaccuracies, especially in terms of real distances; 3. Data from laser lidar, ultrasonic sensors and IR sensors are also contradictory, referring to significantly different obstacle detection ranges. For example, according to lidar data, a set of "passes-frames" is formed, the middle of which build a sequence of target points for the program trajectory of the robot (Figure 2, (3)). From this example it can be seen, that in such problems it is necessary to construct a system of production rules to eliminate contradictions, and the apparatus of this logic is insufficient — the interpretation of data and the purpose of reasoning change. In this regard, we developed a new IGEC approach, discussed in more detail below.

IGEC technology (IGEC, see [1-4]) is the combination of the previously identified (see [6]) four main areas of mathematical approaches, conventionally called ancient Indian, ancient Greek, ancient Egyptian and ancient Chinese. Since each of these approaches (methods) can be applied generally speaking independently, in IGEC possible holistic, in General, four-dimensional representation of the expert knowledge of the tasks and methods of research. This view significantly increases the reliability of problems solving in intelligent robotics (see Figure 2 and [7-19]), the degree of detail and accuracy of the models, and provides tools for formalizing methodological ("inter-traditional") contradictions and ways to eliminate them.

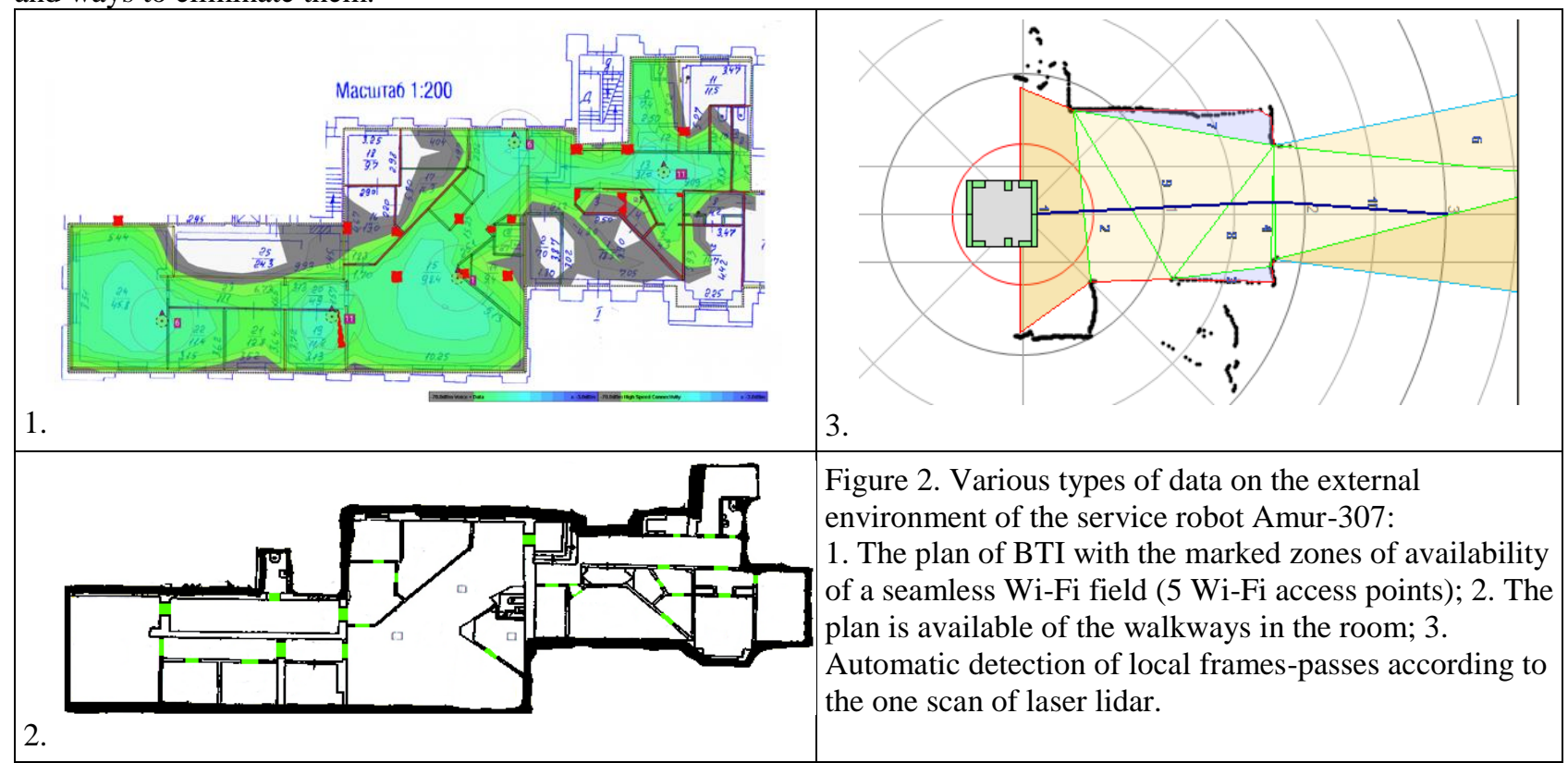

At the same time, the improvement and application of IGEC faces a number of challenges and problems. Thus, the growth of types of mechatronic devices, integration software, applications of intelligent robots creates problems of analysis and design of information-measuring and control systems, training of specialists, adaptation of operators and users to control complex systems. In many areas of knowledge it is necessary to solve very quickly sometimes unexpected, responsible, poorly formalized problems, for example, to understand inconsistent, chaotic instructions; to restore the omission of premises, statements and conclusions; to deal with the change of subject matter, to answer the questions " who acts - a robot or a man?" how will the student/knowledge engineer act with the robot, etc. 


\section{Conclusion}

The main results of the project "Intelligent robotronics" were tested and implemented in practice, also were published during last 3 years in 38 articles (14 Scopus), 2 patents and one Russian State Standard on robots and robotic devices (methods of programming and interacting with operators). Some of the references are below [1-19]. The work is partially supported by RFBR №19-08-01180-а и 19-07-00892 projects.

\section{References}

[1] Pryanichnikov V.E., Katalinic B., Kirilchenko A.A., Khelemendik R.V., Kuvshinov S.V., Vician D., Uglesic A. New Creative Educational Technologies for Inter-university Network // 25th DAAAM International Symposium on Intelligent Manufacturing and Automation. 2014. — Procedia Engineering. 2015. — Vol. 100, — P.259-268. — URL: http://www.sciencedirect.com/science/article/pii/S1877705815003938

[2] Pryanichnikov V. E., Bielic T., Vican D., Katalinich B., Kirsanov K. B., Kuvshinov S. V., Marzanov Yu., Poduraev J. V., Khelemendik R. V., Prysev E. A., Uglesic A., Kharin K.V. Development of educational technology and the network of associated laboratories of robotarium // Information-measuring and control system. - 2015. - Vol. 13, No. 7. - Pp. 7-25. ISSN 2070-0814.

[3] Pryanichnikov V. E., Khelemendik R. V. IGEC Information technology and pentalogics // Computer science and information technology: Proceedings of the international conference. science. Conf. - Saratov: Publishing center "Science", 2016. Pp. 331-333.

[4] Khelemendik R. V., Pryanichnikov V. E. On IGEC technology and its application in the study of chess endings // Scientific service on the Internet: Proceedings of the XIX all-Russian scientific conference (September 19-24, 2017, Novorossiysk). - Moscow: KIAM Keldysh Inst., 2017. Pp. 446-455. - URL: http://keldysh.ru/abrau/2017/proc.pdf

[5] Shipovalov E. A., Pryanichnikov V. E. Auto-planning of missions of mobile robots by onboard computer complexes with hybrid architecture // Extreme robotics. / Collection of abstracts of the International scientific and technical conference. - St. Petersburg: Publishing and printing complex "Gangut", 2017. - Pp. 119-120.6.

[6] Kirilchenko A. A., Pryanichnikov V. E., Rogozin K. V. Limits of reliability and reliability of evidence. Skepticism in mathematics, functions, traditions // Information-measuring and control systems. - 2013. - Vol. 11, No. 4. Pp. 57-65. ISSN 2070-0814.

[7] Pryanichnikov V. E. Artificial intelligence and software and hardware robotic systems. Information-measuring and control systems. - 2018. - Vol. 16, No. 12. - Pp. 3-11. ISSN 2070-0814.

[8] Kuvshinov S. V., Pryanichnikov V. E., Khelemendik R. V., Kharin K. V., Eprikov S. R. Robotariums: scientific and technological base of "Intelligent robotronics" / / Information-measuring and control systems. - 2018. — Vol. 16, No. 12. Pp. 12-23. ISSN 2070-0814.

[9] Pryanichnikov V.E., Chernyshev V.V., Arykantsev V.V., Aryskin A.A., Eprikov S.R., Ksenzenko A.Ya., Petrakov M.S. (2018). Enhancing the Functionality of the Groups of Autonomous Underwater Robots, Proceedings of the 29th DAAAM International Symposium, pp.1319-1325, B. Katalinic (Ed.), Published by DAAAM International, ISBN 978-3-902734-20-4, ISSN 1726-9679, Vienna, Austria DOI: 10.2507/29th.daaam.proceedings.190

[10] Pryanichnikov V.E., Aryskin A.A., Eprikov S.R., Kirsanov K.B., Khelemendik R.V., Ksenzenko A.Ya., Prysev E.A., Travushkin A. S. (2017). Technology of Multi-Agent Control for Industrial Automation with Logical Processing of Contradictions, Proceedings of the 28th DAAAM International Symposium, pp.1202-1207, B. Katalinic (Ed.), Published by DAAAM International, ISBN 978-3-902734-11-2, ISSN 1726-9679, Vienna, Austria. DOI:10.2507/28th.daaam.proceedings.167

[11] B. Katalinich., A.Ya. Ksenzenko, S.V. Kuvshinov, Yu.S. Marzanov, E.A. Prysev, V.E. Pryanichnikov, R.V. Khelemendik, S.R. Epricov // Development of distributed software-hardware robotarium. Extreme robotics. // Proceedings of the International scientific and technical conference. (November 24-25, 2016, St-Petersburg) - Saint Petersburg: OOO"AP4Print", 2016. - 480 p., P.459-465. ISBN 978-5-9909163-3-3.

[12] Extreme robotics. // Abstracts of the International Scientific and Technological Conference. - Saint-Petersburg: "Gangut", 2017. - 272p. URL: http://er.rtc.ru/images/docs/Sbornik_tezisov_ER_2017.pdf

[13] Pryanichnikov V.E., Ksenzenko A.Ya., Kuvshinov S. V., Poduraev Yu. V., Prysev E.A., Khelemendik R.V., Eprikov S. (2016). Intelligent robotronics: hardware-software complexes of robotariums, Proceedings of the 27th DAAAM International Symposium, pp.0225-0229, B. Katalinic (Ed.), Published by DAAAM International, ISBN 978-3902734-08-2, ISSN 1726-9679, Vienna, Austria DOI: 10.2507/27th.daaam.proceedings.033

[14] Bogdanovich A.V., Kirsanov K.B., Pryanichnikov V.E., Khelemendik R.V. Hardware-Software components of intelligent service mobile robots / Information-measuring and control systems (Intelligent and adaptive robots, vol. 14, № 1-2, 2019), M.: Radiotechnika, 2018, vol. 16, № 12, p. 33-39. ISSN 2070-0814.

[15] Bogdanovich A.V., Kirsanov K.B., Khelemendik R.V., Pryanichnikov V.E., Prysev E.A. (2018). Development of Technology for Manufacturing Hardware and Intelligent Levels of the Service Autonomous Mobile Robot AMUR307, Proceedings of the 29th DAAAM International Symposium, pp.1313-1318, B. Katalinic (Ed.), Published by DAAAM International, ISBN 978-3-902734-20-4, ISSN 1726-9679, Vienna, Austria DOI: 10.2507/29th.daaam.proceedings.189 
[16] Stepanova D., Pryanichnikov V.E., Khandorin S., Kuznetsov A., Koulchitskiy A. (2018). High-speed Image Processing Technique Implementation for Pointing and Tracking System Enabling Free-Space Optical Communications, Proceedings of the 29th DAAAM International Symposium, pp.1306-1312, B. Katalinic (Ed.), Published by DAAAM International, ISBN 978-3-902734- 20-4, ISSN 1726-9679, Vienna, Austria DOI: 10.2507/29th.daaam.proceedings. 188

[17] Davydov D.V., Eprikov S.R., Kirsanov K.B., Pryanichnikov V.E. (2017). Service Robots Integrating Software and Remote Reprogramming, Proceedings of the 28th DAAAM International Symposium, pp.1234-1240, B. Katalinic (Ed.), Published by DAAAM International, ISBN 978-3-902734-11-2, ISSN 1726-9679, Vienna, Austria DOI: 10.2507/28th.daaam.proceedings.172.

[18] Ksenzenko A.Ya., Pryanichnikov V.E., Prysev E.A., Chernyshev, V.V. (2017). Design the Contactless Charger and Contactless Data Transfer between Underwater Robot-Satellits and Underwater 6-Legged Vehicle, Proceedings of the 28th DAAAM International Symposium, pp.1197-1201, B. Katalinic (Ed.), Published by DAAAM International, ISBN 978-3-902734-11-2, ISSN 1726-9679, Vienna, Austria. DOI: 10.2507/28th.daaam.proceedings.166.

[19] Kharin, K.V., Kuvshinov S.V., Pryanichnikov, V.E., Anufrieva E.B. (2017). Implementation of Augmented and Virtual Reality Technologies for an Educational and Research Situation Center, Proceedings of the 28th DAAAM International Symposium, pp.0361-0366, B. Katalinic (Ed.), Published by DAAAM International, ISBN 978-3902734-11-2, ISSN 1726-9679, Vienna, Austria. DOI: 10.2507/28th.daaam.proceedings.050. 